A Workshop on Microzonation

(C)Interline Publishing, Bangalore

\title{
Support Vector Machine for Evaluating Seismic Liquefaction Potential Using Shear Wave Velocity
}

\author{
T.G. Sitharam* ${ }^{*}$ and Pijush Samui** \\ *Professor, Department of Civil Engineering, Indian Institute of Science, Bangalore \\ sitharam@civil.iisc.ernet.in \\ ${ }^{* *}$ Research Scholar, Department of Civil Engineering, Indian Institute of Science, Bangalore \\ pijush.phd@gmail.com
}

\begin{abstract}
The use of the shear wave velocity data as a field index for evaluating the liquefaction potential of sands is receiving increased attention because both shear wave velocity and liquefaction resistance are similarly influenced by many of the same factors such as void ratio, state of stress, stress history and geologic age. In this paper, the potential of support vector machines (SVM) based classification approach has been used to assess the liquefaction potential from actual shear wave velocity data. In this approach, an approximate implementation of a structural risk minimization (SRM) induction principle is done, which aims at minimizing a bound on the generalization error of a model rather than minimizing only the mean square error over the data set. Here SVM has been used as a classification tool to predict liquefaction potential of a soil based on shear wave velocity. The dataset consists the information of soil characteristics such as effective vertical stress $\left(\sigma_{\mathrm{v} 0}^{\prime}\right)$, soil type, shear wave velocity $\left(\mathrm{V}_{\mathrm{s}}\right)$ and earthquake parameters such as peak horizontal acceleration $\left(\mathrm{a}_{\max }\right)$ and earthquake magnitude (M). Out of the available 186 datasets, 130 are considered for training and remaining 56 are used for testing the model. The study indicated that SVM can successfully model the complex relationship between seismic parameters, soil parameters and the liquefaction potential. In the model based on soil characteristics, the input parameters used are $\sigma_{\mathrm{v} 0}^{\prime}$, soil type, $\mathrm{V}_{\mathrm{s}}, \mathrm{a}_{\max }$ and $\mathrm{M}$. In the other model based on shear wave velocity alone uses $\mathrm{V}_{\mathrm{s}}, \mathrm{a}_{\max }$ and $\mathrm{M}$ as input parameters. In this paper, it has been demonstrated that Vs alone can be used to predict the liquefaction potential of a soil using support vector machine model.
\end{abstract}

Keywords: liquefaction, shear wave velocity, support vector machine.

\section{Introduction}

Liquefaction in soil is one of the major problems in geotechnical earthquake engineering. It is defined as the transformation of a granular material from a solid to a liquefied state as a consequence of increased pore-water pressure and reduced effective stress [1]. This phenomena was brought to the attention of engineers more so after Niigata (1964) and Alaska (1964) earthquakes. Liquefaction will cause building settlement or tipping, sand boils, ground cracks, landslides, dam instability, highway embankment failures, or other hazards. Such damages are generally of great concern to public safety and are of economic significance. So the assessment of the liquefaction potential due to an earthquake at a site is an imperative task in earthquake geotechnical engineering. A procedure based on Standard Penetration Test (SPT) and cyclic stress ratio (CSR) has been developed by Seed and his colleagues [2-5] based on the use of peak ground acceleration to asses the liquefaction potential of soil. Although SPT-based method is in use (as a standard method) around the world for evaluating liquefaction resistance, it has many drawbacks [6-7]. The first cone penetration test (CPT) based method for liquefaction evaluation was developed by Robertson and Campanella (1985)[7]. CPT method has been revised and updated by many researchers to evaluate liquefaction resistance [8-11]. The engineering 
practitioners commonly use the above two penetration based methods (SPT and CPT) for assessment of liquefaction potential. On the other hand, shear wave velocity $\left(\mathrm{V}_{\mathrm{s}}\right)$ may offer engineers a third tool that is lower cost and provides more physically meaningful measurements. The advantages of using $\mathrm{V}_{\mathrm{s}}$ for evaluating liquefaction potential have been described by many researchers $(12 ; 4 ; 13 ; 14)$. Based on $\mathrm{V}_{\mathrm{s}}$, Andrus et al(1999)[15] and Andrus and Stokoe(2000)[16] have evaluated liquefaction potential for different sites.

Number of approaches based on Vs, both probabilistic and Artificial Neural Network (ANN) methods have been proposed. Juang et al (2001)[17] has proposed a probabilistic framework for liquefaction potential using $\mathrm{V}_{\mathrm{s}}$ data. Goh (2002)[18] successfully used probabilistic neural network (PNN) for assessing liquefaction potential from $\mathrm{V}_{\mathrm{s}}$ data. A major disadvantage of ANN models is that, unlike other statistical models, they provide no information about the relative importance of the various parameters [19]. In ANN, as the knowledge acquired during training is stored in an implicit manner, it is difficult to come up with reasonable interpretation of the overall structure of the network [20]. This lead to the term "black box", which many researchers use while referring to ANN'S behavior. In addition, ANN has some inherent drawbacks such as slow convergence speed, less generalizing performance, arriving at local minimum and over-fitting problems.

This paper proposes an alternative approach based on support vector machine (SVM) to predict the liquefaction of soil using shear wave velocity $\left(\mathrm{V}_{\mathrm{s}}\right)$. SVM, originally developed by Vapnik, is a new machine learning method based on statistical learning theory [21]. In this paper, two models have been developed using SVM. The first model (model I) is based on soil characteristics, which uses the input parameters such as effective vertical stress $\left(\sigma_{\mathrm{v} 0}^{\prime}\right)$, soil type, shear wave velocity $\left(\mathrm{V}_{\mathrm{s}}\right)$, peak horizontal acceleration $\left(\mathrm{a}_{\max }\right)$ and earthquake magnitude $(\mathrm{M})$. The second model (model II) is based on shear wave velocity, which uses $V_{s}, a_{\max }$ and $M$ as input parameters. In this paper, the $V_{s}$ database collected by Andrus and Stokoe (1997)[22] has been used to develop two models to predict liquefaction resistance based on SVM model. The dataset used in this study represents 88 sites that liquefied and 98 sites that did not liquefy. The dataset also contains the information about the soil type, earthquake magnitude, shear wave velocity, etc.

\section{Evaluation of Liquefaction Resistance}

A plot between earthquake load and liquefaction resistance has been shown in Figure 1. A boundary has been drawn in Figure 1 between earthquake load and liquefaction resistance combinations that have and have not produced liquefaction in past earthquakes based on case histories in terms of measured in situ test parameters [23]. In this method, cyclic stress ratio (CSR) is used as earthquake load and cyclic resistance ratio (CRR) is used as liquefaction resistance of a soil. CRR is generally assessed based on field methods such as SPT, CPT and Shear wave velocity.

The most comprehensive study of the application of field-based $\mathrm{V}_{\mathrm{s}}$ measurements to seismicliquefaction assessments has been presented by Andrus and Stokoe (2000). According to Andrus and Stokoe (2000), CRR has been calculated from the following formula:

$$
\begin{aligned}
& \mathrm{CRR}=0.03\left(\frac{\mathrm{V}_{\mathrm{s}}}{100}\right)^{2}+0.9\left(\frac{1}{\mathrm{~V}_{\mathrm{slc}}-\mathrm{V}_{\mathrm{sl}}}-\frac{1}{\mathrm{~V}_{\mathrm{slc}}}\right) \\
& \text { Where } \mathrm{V}_{\mathrm{sl}}=\mathrm{V}_{\mathrm{s}}\left(\frac{\mathrm{P}_{\mathrm{a}}}{\sigma_{\mathrm{v} 0}^{\prime}}\right)^{0.25}
\end{aligned}
$$


$\mathrm{V}_{\mathrm{sl}}=$ overburden-stress correlated shear wave velocity;

$\mathrm{P}_{\mathrm{a}}=$ atmospheric pressure approximated by $100 \mathrm{kPa}$; and $\sigma_{\mathrm{v} 0}^{\prime}=$ initial vertical effective stress in $\mathrm{kPa}$.

For sands and gravels

$$
\begin{aligned}
\mathrm{V}_{\text {slc }} & =220, \text { fine content }(\mathrm{FC}) \leq 5 \% \\
& =210, \mathrm{FC} \approx 20 \% \\
& =200, \mathrm{FC} \geq 35 \%
\end{aligned}
$$

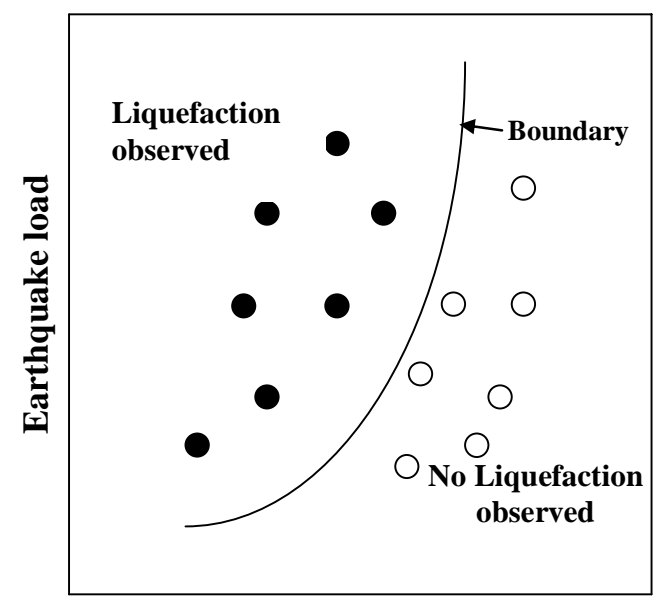

\section{Liquefaction resistance}

Figure 1 Boundary indicates minimum value of liquefaction resistance parameter required to prevent liquefaction

The CSR $=\frac{\tau_{a v}}{\sigma_{v 0}^{\prime}}$, at a particular depth in a level soil deposit has been calculated by using following formula [3]:

$$
\mathrm{CSR}=\frac{\tau_{\mathrm{av}}}{\sigma_{\mathrm{V}}}=0.65\left(\frac{\mathrm{a}_{\max }}{\mathrm{g}}\right)\left(\frac{\sigma_{\mathrm{V}}}{\sigma_{\mathrm{V}}^{\prime}}\right) \mathrm{r}_{\mathrm{d}}
$$

Where $\tau_{\mathrm{av}}=$ average equivalent uniform cyclic shear stress caused by the earthquake and is assumed to be 0.65 of the maximum induced stress; $\mathrm{a}_{\max }=$ peak horizontal ground surface acceleration; $\mathrm{g}=$ acceleration of gravity; $\sigma_{\mathrm{v}}^{\prime}=$ initial vertical effective stress at the depth in question; $\sigma_{\mathrm{v}}=$ total overburden stress at the same depth and $r_{d}=$ shear stress reduction coefficient to adjust for the flexibility of the soil profile and it has been estimated from the chart by Seed and Idriss(1971).

\section{Support Vector Machine (SVM) Model}

SVM has recently emerged as an elegant pattern recognition tool and a better alternative to ANN methods. The method has been developed by Vapnik (1995) and is gaining popularity due to many attractive features. The formulation is based on Structural Risk Minimisation (SRM) which has been shown to be superior to the Empirical Risk Minimisation (ERM) used in conventional neural networks [21]. This section of the paper serves an introduction to this relatively new technique. Details of this method can be found in Boser et al. (1992, Cortes and Vapnik (1995), Gualtieri et al. (1999), and Vapnik (1998)[24-27]. A binary classification problem is considered having a set of training vectors (D) belonging to two separate classes (liquefaction and no-liquefaction).

$$
\mathrm{D}=\left\{\left(\mathrm{x}^{1}, \mathrm{y}^{1}\right), \ldots \ldots \ldots,\left(\mathrm{x}^{1}, \mathrm{y}^{1}\right)\right\} \quad \mathrm{x} \in \mathrm{R}^{\mathrm{n}}, \mathrm{y} \in\{-1,+1\}
$$


Where $\mathrm{x} \in \mathrm{R}^{\mathrm{n}}$ is an $\mathrm{n}$-dimensional data vector with each sample belonging to either of two classes labelled as $\mathrm{y} \in\{-1,+1\}$, and 1 is the number of training data. The main aim is to find a generalized classifier that can distinguish the two classes $(-1,+1)$ from the set of the training vectors mentioned above (D). For a set of data, this would mean a linear hyper plane defined by equation (5) which can distinguish the two classes:

$$
\mathrm{f}(\mathrm{x})=\mathrm{w} \cdot \mathrm{x}+\mathrm{b}=0
$$

Where, $\mathrm{w} \in \mathrm{R}^{n}$ determines the orientation of a discriminating hyperplane, $\mathrm{b} \in \mathrm{R}$ is a bias. For the linearly separable case, a separating hyperplane can be defined for the two classes (liquefaction and no-liquefaction cases) as:

$$
\begin{aligned}
& \text { w. } x_{i}+b \geq 1\left(\text { for } y_{i}=1\right) \longrightarrow \text { No-liquefaction } \\
& \text { w. } x_{i}+b \leq-1\left(\text { for } y_{i}=-1\right) \longrightarrow \text { Liquefaction }
\end{aligned}
$$

The above two equation can be combined as :

$\mathrm{y}_{\mathrm{i}}\left(\mathrm{w} \cdot \mathrm{x}_{\mathrm{i}}+\mathrm{b}\right) \geq 1$

Sometimes, due to the noise or mixture of classes introduced during the selection of training data, variables $\xi_{\mathrm{i}}>0$, called slack variables, are used due to the effects of misclassification. So the equation (7) can be written as:

$$
y_{i}\left(w \cdot x_{i}+b\right) \geq 1-\xi_{i}
$$

The perpendicular distance from the origin to the hyperplane for liquefaction class $w_{1} \cdot x_{i}+b=-1$ is $\frac{|1+b|}{\|w\|}$. Similarly, the perpendicular distance from the origin to the hyperplane for non liquefaction

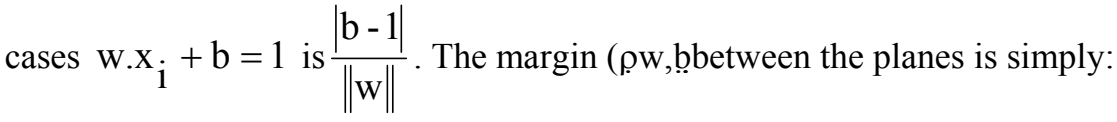

$$
\rho(w, b)=\frac{2}{\|w\|}
$$

The optimal hyperplane is located where the margin between two classes of interest is maximized and the error is minimized. The maximization of this margin leads to the following constrained optimization problem

$$
\begin{aligned}
& \text { Minimize: } \frac{1}{2}\|\mathrm{w}\|^{2}+\mathrm{C} \sum_{\mathrm{i}=1}^{1} \xi_{\mathrm{i}} \\
& \text { Subjected to: } \quad \mathrm{y}_{\mathrm{i}}\left(\mathrm{w}_{\mathrm{x}} \mathrm{x}_{\mathrm{i}}+\mathrm{b}\right) \geq 1-\xi_{\mathrm{i}}
\end{aligned}
$$

The constant (called capacity factor) $0<\mathrm{C}<\infty$, a parameter defines the trade-off between the number of misclassification in the training data and the maximization of margin. This optimization problem is solved by Lagrangian Multipliers [27]. According to the Karush-Kuhn-Tucker (KKT) optimality condition [28], some of the multipliers will be zero. The nonzero multipliers are called support vectors (see Figure 2). In conceptual terms, the support vectors are those data points that lie closest to the optimal hyperplane and are therefore the most difficult to classify. The value of $\mathrm{w}$ and $\mathrm{b}$ are calculated 
from $\mathrm{w}=\sum_{\mathrm{i}=1}^{1} \mathrm{y}_{\mathrm{i}} \alpha_{\mathrm{i}} \mathrm{x}_{\mathrm{i}}$ and $\mathrm{b}=-\frac{1}{2} \mathrm{w}\left[\mathrm{x}_{+1}+\mathrm{x}_{-1}\right]$, where $\mathrm{x}_{+1}$ and $\mathrm{x}_{-1}$ are the support vectors of class labels +1 (no-liquefaction) and -1 (liquefaction) respectively. The classifier can then be constructed as:

$$
f(x)=\operatorname{sign}(w \cdot x+b)
$$

Where sign is the signum function. It gives +1 if the element is greater than or equal to zero and -1 if it is less than zero.

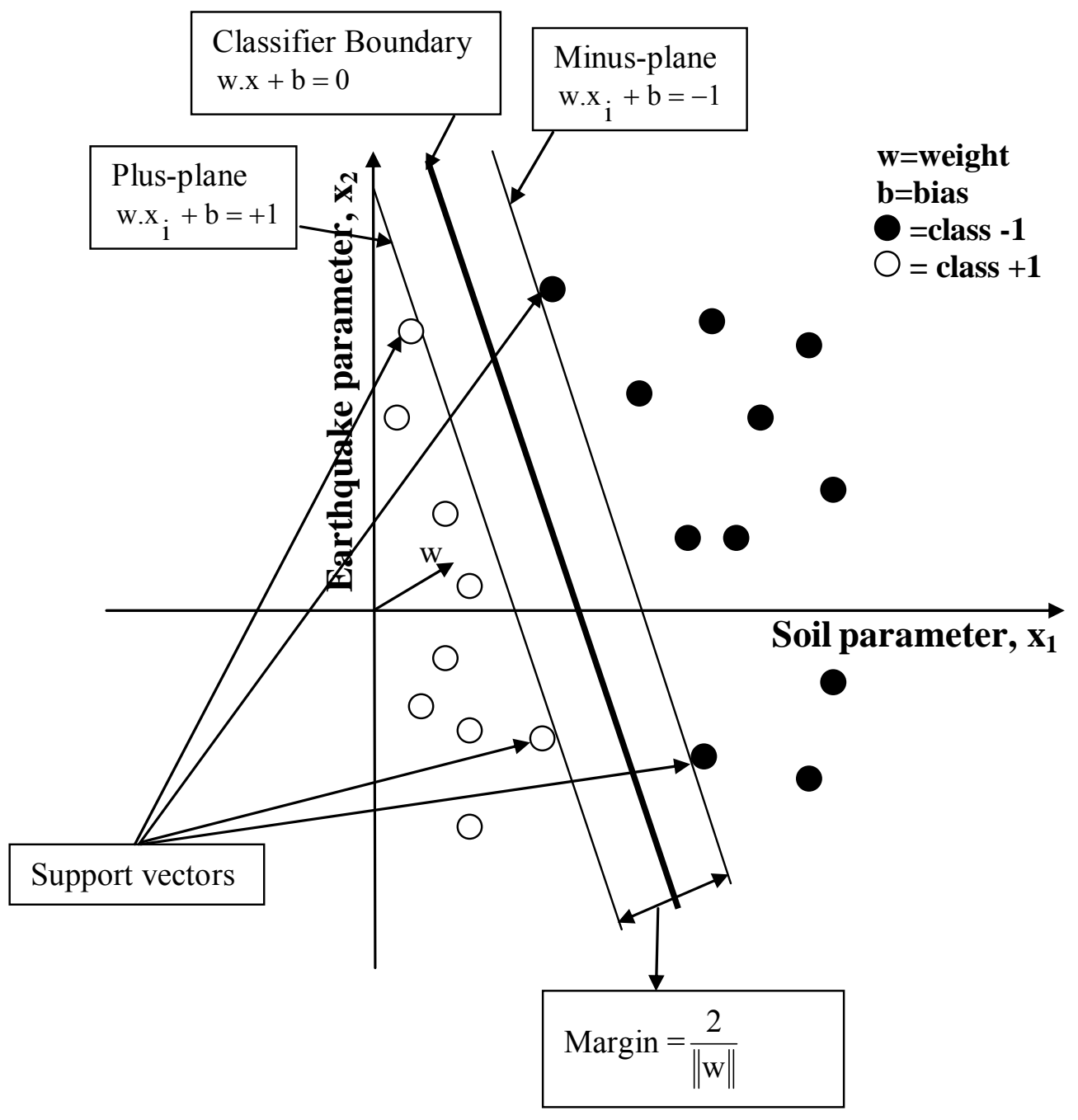

Figure 2 Support vectors with maximum margin

In case where linear supporting hyper plane is inappropriate, SVM maps input data into a high dimensional feature space through some nonlinear mapping [24]. This method easily converts a linear classification learning algorithm into a non-linear one, by mapping the original observations into a higher-dimensional non-linear space so that linear classification in the new space is equivalent to nonlinear classification in the original space. Kernel function has been introduced instead of feature 
$\operatorname{space}(\Phi(\mathrm{x}))$ to reduce computational demand [25; 29]. Polynomial, radial basis functions and certain sigmoid functions has been used as a kernel functions. To get the equation (5), same procedures have been applied as in linear case.

\section{Methodology}

The main scope of this study is to implement SVM in the prediction of liquefaction based on $\mathrm{V}_{\mathrm{s}}$ measurements. Two models have been developed using SVM to predict liquefaction resistance based on field Vs data. In the model I, based on soil characteristics, the input parameters are $\sigma_{\mathrm{v} 0}^{\prime}$, soil type, $\mathrm{V}_{\mathrm{s}}, \mathrm{a}_{\max }$, and M. In the second method, model II, only shear wave velocity has been used to characterize the soil properties. In model II, $\mathrm{V}_{\mathrm{s}}, \mathrm{a}_{\max }$, and $\mathrm{M}$ have been chosen as input parameters. In this paper, binary classification is used (only Yes /No) for Liquefaction classifier. However, one can attempt, multi-classification [30] to determine three types such as liquefaction, no liquefaction and marginal liquefaction.

\subsection{Model Based on Soil Characteristics (Model I)}

Liquefaction of soils during earthquakes is dependent on both seismic and soil parameters. So, the parameters that have been selected as input parameters for the model based on soil characteristics are $\sigma_{v}^{\prime}$, soil type and $V_{s}$, and two earthquake parameters such as $a_{\max }$ and $M$. The data for the soil type has been taken from the work of Andrus and Stokoe (1997). The dataset represented 88 sites that liquefied and 98 sites that did not liquefy (Table 3 and 4). The data is normalized against their maximum values [31]. To use these data for classification purpose, a value of -1 is assigned to the liquefied sites while a value of 1 is assigned to the non-liquefied sites. So, the output of the model will be either 1 or -1 .

In carrying out the formulation, the data has been divided into two sub-sets such as

a) A training dataset: This is required to construct the model. In this study, 130 out of the 186 data are considered for training. Table 3 shows the training dataset.

b) A testing dataset: This is required to estimate the model performance. In this study, the remaining 56 data is considered for testing. Table 4 shows the testing dataset.

The data has been divided into training and testing datasets using sorting method, to maintain statistical consistency. The statistical consistency of training and testing datasets improve the performance of the model and helps in evaluating them better (similar to what has been used for ANN by Shahin et al., 2000[32]).

The application of SVM for this problem requires the proper selection of different design parameters. In this study, the design parameters are selected by carrying out a parametric study. Through this parametric study, appropriate $\mathrm{C}$ value and kernel were selected. In case of SVM training, three types of kernel functions- namely, radial basis function kernel, polynomial kernel, and bspline kernel have been used. The values of $\mathrm{C}$ as well as other kernel specific parameters have to be set to their optimal values during the model training process.

\subsection{Model Based on Shear Wave Velocity (Model II)}

In the model based on soil characteristic, $\sigma_{v}^{\prime}$, soil type are used as input parameters. Multi channel analysis of surface wave (MASW) method or Spectral Analysis of Surface wave (SASW) methods are (for measurement of shear wave velocity profiles in field based on Raleigh waves) non destructive techniques and does not have a provision to get density or \% of fines. In addition to the shear wave velocity survey, one needs to drill boreholes and collect the samples to obtain the information on density and \%fines. Thus in this study, we have attempted to develop the model based on shear wave velocity alone to predict the liquefaction resistance. The parameters used in this model II are $\mathrm{V}_{\mathrm{s}}$ along with earthquake parameters such as $\mathrm{a}_{\max }$ and $\mathrm{M}$. Even here, the training dataset, testing dataset, normalization technique and different kernel functions are same as the one used for Model I. 
Both the programs (model based on soil characteristic, model I, and only on shear wave velocity, model II) are constructed using the MATLAB [33].

\section{Results and Discussion}

The optimum "C" value has been selected by carrying out a parametric study. A large value of C assigns higher penalties to errors so that the SVM is trained to minimize error with lower generalization while a small value of $\mathrm{C}$ assigns fewer penalties to errors; this allows the minimization of margin with errors, thus higher generalization ability. If C goes to infinitely large, SVM would not allow the occurrence of any error and result in a complex model, whereas when $\mathrm{C}$ goes to zero, the result would tolerate a large amount of errors and the model would be less complex. So it is necessary to investigate the impact of $\mathrm{C}$ value on testing performance (\%) as well as number of support vectors. The testing performance $(\%)$ is calculated by:

Testing performance $(\%)=\left(\frac{\text { No of data predicted accurately by SVM }}{\text { Total data }}\right) \times 100$

From figure 3, it is clear that $\mathrm{C}$ value does not affect the testing accuracy (\%) of the model with radial basis function as well as bspline kernel in model I. Figure 3 shows generally that the number of support vectors is decreasing with increasing $\mathrm{C}$ value for each kernel for model I. Table 1 shows training, testing performance and design $\mathrm{C}$ value for each kernel type with corresponding number of support vectors. For best model and best testing performance, less number of support vectors is desirable. It also shows that radial basis function gives the best performance( using design $\mathrm{C}$ value and corresponding number of support vectors as shown in Table 1) for the model I (based on all soil characteristics). The radial basis function has an overall success rate of $98.21 \%$, with no errors in training dataset and one data error in the testing dataset. Table 1 also highlights that the polynomial kernel produces the lowest number of support vectors.

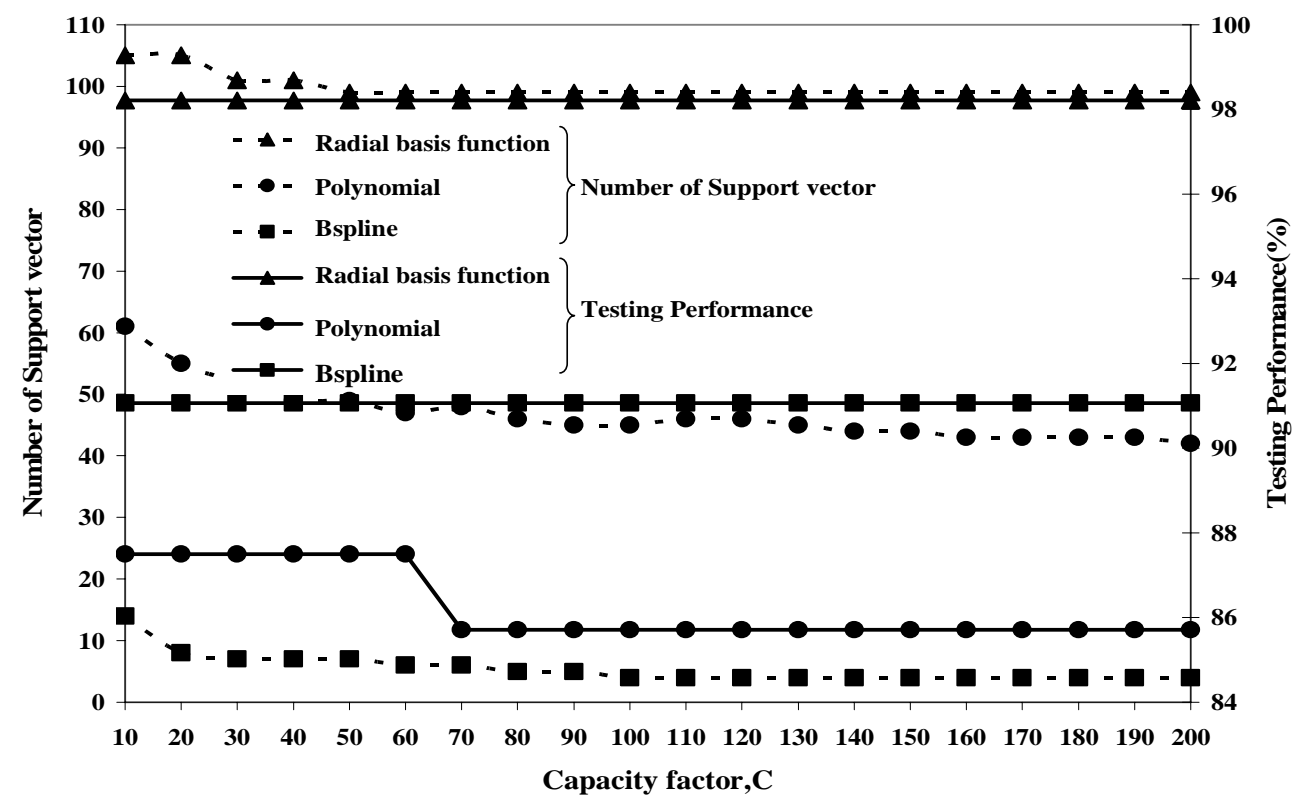

Figure 3 Variation of testing performance (\%) and Number of Support Vectors with capacity factor (C) values for the model based on soil characteristic data(model I) using different kernels

For the model II (based on shear wave velocity), figure 4 shows the variation of number of support vectors and testing performance (\%) with $\mathrm{C}$ value. It also shows that number of support vector as well 
as testing performance (\%) does not have any trend with $\mathrm{C}$ value for different kernels. The training and testing performance of each kernel, design $\mathrm{C}$ value and number of support vector are summarized in Table 2. A testing accuracy (\%) of $91.07 \%$ has been achieved with radial basis function kernel. Out of 56 testing data only five data has been incorrectly classified. For the model II (based on shear wave velocity) radial basis function gives best result( using design $\mathrm{C}$ value and corresponding number of support vectors as shown in Table 2) which produces lowest number of support vectors. The performance of model I is slightly better than the model II. This also demonstrates that for SVM classification, the possibility of finding optimum hyperplane to separate the classes is higher with 5 input variables in model I than with 3 input variables in model II. Tables 3 and 4 show the performance of both models using radial basis function for training and testing datasets respectively.

An additional dataset (as listed in Table5) which is not part of the training and testing dataset (which was presented earlier)) have been collected from the work of Andrus and Stokoe (1997).

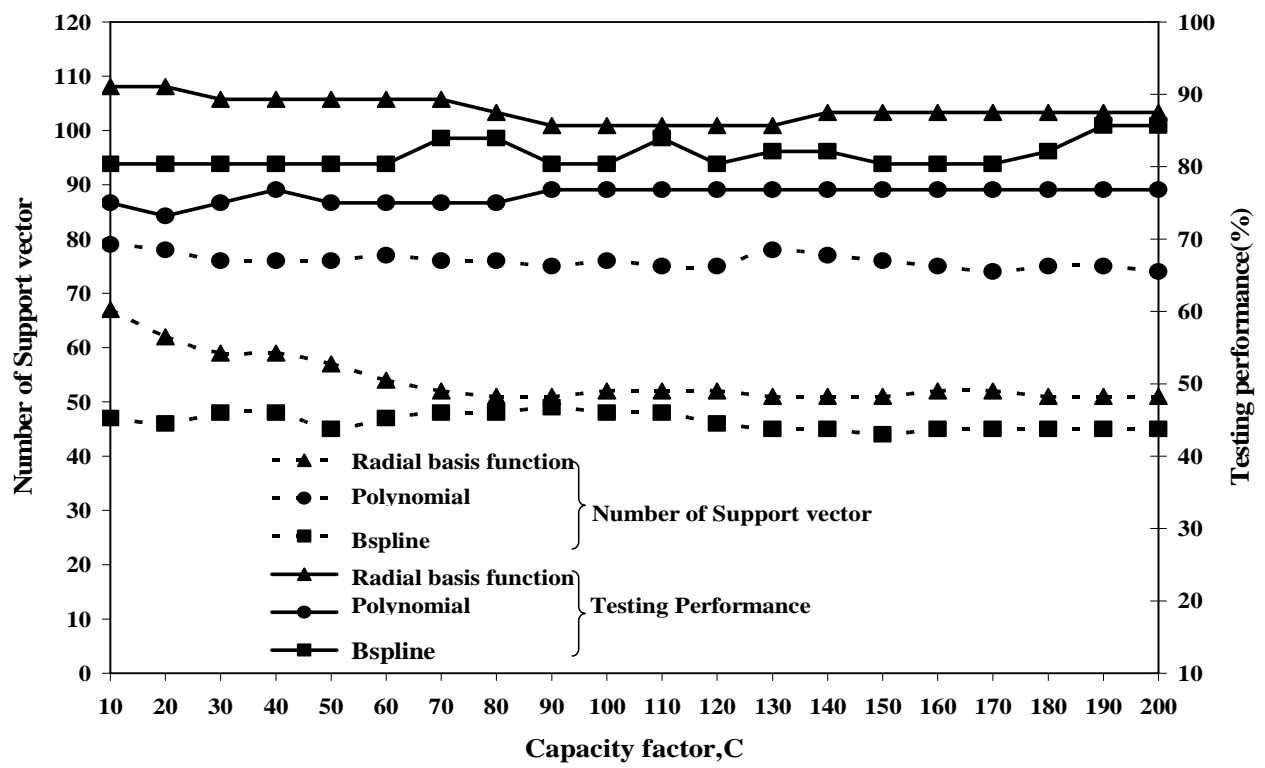

Figure 4 Variation of testing performance (\%) and Number of Support

Vectors with capacity factor(C) values for the model based on shear wave velocity (model II) using different kernels

The performance of the above two developed models has been assessed for this dataset and the same has been reported in Table 5. For both the models, only one data has been misclassified. The prediction has been done with radial basis function for both models. The results presented in Table 5 highlights very clearly that SVM is good tool to predict liquefaction resistance of soils.

Table 1 General performance of SVM for different kernels for model based on soil characteristic (Model I).

\begin{tabular}{|c|c|c|c|c|}
\hline kernel & C & $\begin{array}{c}\text { Training } \\
\text { performance (\%) }\end{array}$ & $\begin{array}{c}\text { Testing } \\
\text { performance (\%) }\end{array}$ & $\begin{array}{c}\text { Number of } \\
\text { support vectors }\end{array}$ \\
\hline $\begin{array}{c}\text { Radial basis function, } \\
\text { width }(\sigma)=0.08\end{array}$ & 50 & 100 & 98.21 & 99 \\
\hline Polynomial, degree $=3$ & 60 & 90 & 87.5 & 47 \\
\hline Bspline, degree=2 & 100 & 100 & 91.07 & 4 \\
\hline
\end{tabular}


Table 2 General performance of SVM for different kernels for model based on shear wave velocity (Model II).

\begin{tabular}{|c|c|c|c|c|}
\hline kernel & C & $\begin{array}{c}\text { Training } \\
\text { performance (\%) }\end{array}$ & $\begin{array}{c}\text { Testing } \\
\text { performance (\%) }\end{array}$ & $\begin{array}{c}\text { Number of } \\
\text { support vectors }\end{array}$ \\
\hline $\begin{array}{c}\text { Radial basis function, } \\
\text { width }(\sigma)=0.1\end{array}$ & 20 & 93.08 & 91.07 & 62 \\
\hline Polynomial, degree =3 & 170 & 80 & 76.79 & 74 \\
\hline Bspline, degree=2 & 190 & 86.15 & 85.71 & 45 \\
\hline
\end{tabular}

Table 3 Performance of training dataset for both models using radial basis function

\begin{tabular}{|c|c|c|c|c|c|c|c|}
\hline \multirow[t]{2}{*}{.$\sigma_{\mathrm{v}}^{\prime}$} & \multirow[t]{2}{*}{$a_{\max }$} & \multirow{2}{*}{$\begin{array}{l}\text { Soil } \\
\text { type }\end{array}$} & \multirow[t]{2}{*}{ M } & \multirow[t]{2}{*}{$\mathrm{V}_{\mathrm{s}}$} & \multirow{2}{*}{$\begin{array}{l}\text { Actual } \\
\text { class }\end{array}$} & \multicolumn{2}{|c|}{ Predicted class } \\
\hline & & & & & & $\begin{array}{c}\text { Model } \\
\text { I }\end{array}$ & $\begin{array}{c}\text { Model } \\
\text { II }\end{array}$ \\
\hline 62.1 & 0.36 & 4 & 7.7 & 136 & -1 & -1 & -1 \\
\hline 58.2 & 0.36 & 4 & 7.7 & 173 & -1 & -1 & -1 \\
\hline 140.8 & 0.32 & 1.5 & 7.7 & 177 & 1 & 1 & 1 \\
\hline 140.8 & 0.32 & 1.5 & 7.7 & 200 & 1 & 1 & 1 \\
\hline 123.5 & 0.32 & 2.5 & 7.7 & 149 & -1 & -1 & -1 \\
\hline 54.7 & 0.16 & 3 & 7.5 & 115 & -1 & -1 & -1 \\
\hline 57.8 & 0.12 & 1 & 6.5 & 105 & 1 & 1 & 1 \\
\hline 50.1 & 0.12 & 1.5 & 7.1 & 98 & -1 & -1 & -1 \\
\hline 43.6 & 0.12 & 1 & 7.1 & 101 & -1 & -1 & -1 \\
\hline 101.2 & 0.12 & 1 & 7.1 & 143 & 1 & 1 & -1 \\
\hline 36 & 0.46 & 4 & 6.9 & 206 & 1 & 1 & 1 \\
\hline 55.8 & 0.21 & 2 & 6.5 & 90 & -1 & -1 & -1 \\
\hline 38.1 & 0.51 & 2 & 6.5 & 126 & -1 & -1 & -1 \\
\hline 48 & 0.5 & 2 & 6.5 & 131 & -1 & -1 & -1 \\
\hline 46.6 & 0.5 & 2.5 & 6.5 & 164 & 1 & 1 & 1 \\
\hline 120.2 & 0.08 & 2 & 5.9 & 195 & 1 & 1 & 1 \\
\hline 57.8 & 0.27 & 1.5 & 5.9 & 115 & -1 & -1 & -1 \\
\hline 55.8 & 0.2 & 2 & 5.9 & 90 & -1 & -1 & -1 \\
\hline 54.8 & 0.3 & 2.5 & 5.9 & 101 & -1 & -1 & -1 \\
\hline 48 & 0.02 & 2 & 5.9 & 133 & 1 & 1 & 1 \\
\hline 77.5 & 0.14 & 2.5 & 7.1 & 178 & 1 & 1 & 1 \\
\hline 79.4 & 0.16 & 2 & 7.1 & 121 & -1 & -1 & -1 \\
\hline 45.6 & 0.36 & 4 & 6.9 & 122 & -1 & -1 & -1 \\
\hline 32.9 & 0.36 & 4 & 6.9 & 128 & -1 & -1 & -1 \\
\hline 32.4 & 0.36 & 4 & 6.9 & 107 & -1 & -1 & -1 \\
\hline 38.1 & 0.36 & 4 & 6.9 & 154 & -1 & -1 & -1 \\
\hline 32.7 & 0.3 & 4 & 6.9 & 105 & -1 & -1 & -1 \\
\hline 28.7 & 0.29 & 4 & 6.9 & 106 & -1 & -1 & -1 \\
\hline 53.5 & 0.46 & 4 & 6.9 & 274 & 1 & 1 & 1 \\
\hline 59.2 & 0.06 & 2 & 6 & 155 & 1 & 1 & 1 \\
\hline 28.7 & 0.42 & 2 & 7.1 & 116 & -1 & -1 & -1 \\
\hline 35.4 & 0.22 & 1.5 & 6.6 & 127 & 1 & 1 & 1 \\
\hline 35.4 & 0.18 & 1.5 & 6.6 & 146 & 1 & 1 & 1 \\
\hline
\end{tabular}

\begin{tabular}{|c|c|c|c|c|c|c|c|}
\hline \multirow[t]{2}{*}{$\sigma_{\mathrm{v}}^{\prime}$} & \multirow[t]{2}{*}{$\mathrm{a}_{\max }$} & \multirow{2}{*}{$\begin{array}{l}\text { Soil } \\
\text { type }\end{array}$} & \multirow[t]{2}{*}{$\mathrm{M}$} & \multirow[t]{2}{*}{$\mathrm{V}_{\mathrm{s}}$} & \multirow{2}{*}{$\begin{array}{c}\text { Actual } \\
\text { class }\end{array}$} & \multicolumn{2}{|c|}{ Predicted class } \\
\hline & & & & & & $\begin{array}{c}\text { Model } \\
\text { I }\end{array}$ & $\begin{array}{c}\text { Model } \\
\text { II }\end{array}$ \\
\hline 35.4 & 0.18 & 1.5 & 6.6 & 130 & 1 & 1 & 1 \\
\hline 35.4 & 0.04 & 1.5 & 6.2 & 127 & 1 & 1 & 1 \\
\hline 70 & 0.19 & 4 & 8.3 & 144 & -1 & -1 & -1 \\
\hline 35.4 & 0.18 & 1.5 & 6.2 & 133 & 1 & 1 & 1 \\
\hline 35.4 & 0.05 & 1.5 & 6.2 & 146 & 1 & 1 & 1 \\
\hline 71 & 0.15 & 3 & 7.1 & 163 & -1 & -1 & -1 \\
\hline 35.4 & 0.05 & 1.5 & 6.2 & 130 & 1 & 1 & 1 \\
\hline 35.4 & 0.16 & 1.5 & 7.6 & 127 & 1 & 1 & 1 \\
\hline 35.4 & 0.16 & 1.5 & 7.6 & 130 & 1 & 1 & 1 \\
\hline 53.9 & 0.12 & 1.5 & 5.9 & 127 & 1 & 1 & 1 \\
\hline 55.8 & 0.11 & 2 & 5.9 & 90 & 1 & 1 & 1 \\
\hline 38.1 & 0.06 & 2 & 5.9 & 126 & 1 & 1 & 1 \\
\hline 57.8 & 0.24 & 1 & 5.9 & 105 & 1 & 1 & 1 \\
\hline 46.6 & 0.03 & 2.5 & 5.9 & 164 & 1 & 1 & 1 \\
\hline 57.9 & 0.2 & 3 & 6.9 & 135 & -1 & -1 & -1 \\
\hline 53.9 & 0.2 & 1.5 & 6.5 & 124 & 1 & 1 & 1 \\
\hline 38.1 & 0.19 & 2 & 6.5 & 126 & 1 & 1 & 1 \\
\hline 54.8 & 0.2 & 2.5 & 6.5 & 101 & 1 & 1 & 1 \\
\hline 48 & 0.18 & 2 & 6.5 & 131 & 1 & 1 & 1 \\
\hline 46.6 & 0.18 & 2.5 & 6.5 & 173 & 1 & 1 & 1 \\
\hline 63.5 & 0.14 & 2 & 7.1 & 130 & -1 & -1 & -1 \\
\hline 83 & 0.14 & 2 & 7.1 & 157 & -1 & -1 & -1 \\
\hline 78.6 & 0.14 & 2 & 7.1 & 148 & -1 & -1 & -1 \\
\hline 90.6 & 0.14 & 2 & 7.1 & 137 & -1 & -1 & -1 \\
\hline 82.5 & 0.14 & 2 & 7.1 & 146 & -1 & -1 & -1 \\
\hline 48.8 & 0.14 & 3 & 7.1 & 154 & -1 & -1 & -1 \\
\hline 63.9 & 0.15 & 2.5 & 7.1 & 143 & -1 & -1 & -1 \\
\hline 78.8 & 0.16 & 1.5 & 7.1 & 117 & -1 & -1 & -1 \\
\hline 79.4 & 0.16 & 2 & 7.1 & 138 & -1 & -1 & -1 \\
\hline 82 & 0.16 & 2 & 7.1 & 145 & 1 & 1 & -1 \\
\hline 83.3 & 0.16 & 2 & 7.1 & 133 & 1 & 1 & -1 \\
\hline 92.4 & 0.24 & 2.5 & 7.1 & 148 & -1 & -1 & -1 \\
\hline 85.8 & 0.24 & 3 & 7.1 & 179 & -1 & -1 & -1 \\
\hline 86.2 & 0.24 & 3 & 7.1 & 145 & -1 & -1 & -1 \\
\hline 75.2 & 0.27 & 2.5 & 7.1 & 212 & 1 & 1 & 1 \\
\hline 77 & 0.27 & 2.5 & 7.1 & 204 & 1 & 1 & 1 \\
\hline
\end{tabular}




\begin{tabular}{|c|c|c|c|c|c|c|c|}
\hline 60.9 & 0.27 & 2.5 & 7.1 & 116 & -1 & -1 & -1 \\
\hline 82.2 & 0.15 & 2.5 & 7.1 & 120 & -1 & -1 & -1 \\
\hline 82.2 & 0.15 & 2.5 & 7.1 & 105 & -1 & -1 & -1 \\
\hline 105.7 & 0.15 & 3 & 7.1 & 220 & 1 & 1 & 1 \\
\hline 58.2 & 0.19 & 4 & 7.1 & 161 & 1 & 1 & 1 \\
\hline 58.2 & 0.19 & 4 & 7.1 & 173 & 1 & 1 & 1 \\
\hline 140.8 & 0.15 & 1.5 & 7.1 & 195 & 1 & 1 & 1 \\
\hline 123.5 & 0.15 & 2.5 & 7.1 & 131 & 1 & 1 & -1 \\
\hline 123.5 & 0.15 & 2.5 & 7.1 & 146 & 1 & 1 & -1 \\
\hline 123.5 & 0.15 & 2.5 & 7.1 & 168 & 1 & 1 & 1 \\
\hline 41 & 0.42 & 2 & 7.1 & 126 & 1 & 1 & -1 \\
\hline 57.8 & 0.42 & 2 & 7.1 & 135 & 1 & 1 & -1 \\
\hline 30.5 & 0.42 & 3 & 7.1 & 126 & -1 & -1 & -1 \\
\hline 42.4 & 0.25 & 3 & 7.1 & 130 & -1 & -1 & -1 \\
\hline 87.7 & 0.25 & 3 & 7.1 & 209 & -1 & -1 & -1 \\
\hline 39.6 & 0.25 & 3 & 7.1 & 143 & -1 & -1 & -1 \\
\hline 98.8 & 0.5 & 4 & 6.9 & 197 & -1 & -1 & -1 \\
\hline 139.1 & 0.48 & 3 & 6.9 & 149 & 1 & 1 & 1 \\
\hline 58.2 & 0.36 & 4 & 7.7 & 161 & -1 & -1 & -1 \\
\hline 123.5 & 0.32 & 2.5 & 7.7 & 131 & -1 & -1 & -1 \\
\hline 123.5 & 0.32 & 2.5 & 7.7 & 168 & -1 & -1 & -1 \\
\hline 73.7 & 0.12 & 1 & 7.1 & 103 & -1 & -1 & -1 \\
\hline 57.8 & 0.13 & 1.5 & 6.5 & 115 & 1 & 1 & 1 \\
\hline 54.8 & 0.12 & 2.5 & 6.5 & 101 & 1 & 1 & 1 \\
\hline 59.2 & 0.08 & 2 & 5.9 & 155 & 1 & 1 & 1 \\
\hline 38.1 & 0.06 & 2 & 5.9 & 126 & 1 & 1 & 1 \\
\hline 48 & 0.02 & 2 & 5.9 & 131 & 1 & 1 & 1 \\
\hline 46.6 & 0.02 & 2.5 & 5.9 & 173 & 1 & 1 & 1 \\
\hline 36 & 0.36 & 4 & 6.9 & 102 & -1 & -1 & -1 \\
\hline 33.8 & 0.36 & 4 & 6.9 & 131 & -1 & -1 & -1 \\
\hline 36 & 0.3 & 4 & 6.9 & 122 & -1 & -1 & -1 \\
\hline 27.8 & 0.29 & 4 & 6.9 & 105 & -1 & -1 & -1 \\
\hline 57.4 & 0.23 & 4 & 6.9 & 271 & 1 & 1 & 1 \\
\hline 35.4 & 0.22 & 1.5 & 6.6 & 130 & 1 & 1 & 1 \\
\hline 35.4 & 0.18 & 1.5 & 6.6 & 127 & 1 & 1 & 1 \\
\hline 35.4 & 0.04 & 1.5 & 6.2 & 133 & 1 & 1 & 1 \\
\hline 35.4 & 0.18 & 1.5 & 6.2 & 130 & 1 & 1 & 1 \\
\hline 35.4 & 0.05 & 1.5 & 6.2 & 127 & 1 & 1 & 1 \\
\hline 35.4 & 0.16 & 1.5 & 7.6 & 133 & 1 & 1 & 1 \\
\hline 140.2 & 0.1 & 2.5 & 6.5 & 150 & 1 & 1 & 1 \\
\hline 54.8 & 0.13 & 2.5 & 5.9 & 101 & 1 & 1 & 1 \\
\hline 48 & 0.03 & 2 & 5.9 & 133 & 1 & 1 & 1 \\
\hline 53.9 & 0.2 & 1.5 & 6.5 & 127 & 1 & 1 & 1 \\
\hline 55.8 & 0.2 & 2 & 6.5 & 90 & 1 & 1 & -1 \\
\hline 46.6 & 0.18 & 2.5 & 6.5 & 164 & 1 & 1 & 1 \\
\hline 83.7 & 0.14 & 2 & 7.1 & 157 & -1 & -1 & -1 \\
\hline 86.4 & 0.14 & 2 & 7.1 & 152 & -1 & -1 & -1 \\
\hline 84.7 & 0.16 & 1.5 & 7.1 & 143 & -1 & -1 & -1 \\
\hline 79.4 & 0.16 & 1.5 & 7.1 & 152 & -1 & -1 & -1 \\
\hline
\end{tabular}

\begin{tabular}{|c|c|c|c|c|c|c|c|}
\hline$\sigma_{\mathrm{v}}^{\prime}$ & $\mathrm{a}_{\max }$ & \multirow{2}{*}{$\begin{array}{c}\text { Soil } \\
\text { type }\end{array}$} & & $\mathrm{M}$ & $\mathrm{V}_{\mathrm{s}}$ & \multirow{2}{*}{$\begin{array}{c}\text { Actual } \\
\text { class }\end{array}$} & \multicolumn{2}{|c|}{ Predicted class } \\
\cline { 6 - 9 } & & & & & & $\begin{array}{c}\text { Model } \\
\mathrm{I}\end{array}$ & $\begin{array}{c}\text { Model } \\
\text { II }\end{array}$ \\
\hline 82.4 & 0.24 & 2.5 & 7.1 & 134 & -1 & -1 & -1 \\
\hline 85.8 & 0.24 & 3 & 7.1 & 145 & -1 & -1 & -1 \\
\hline & & & & & & & \\
\hline 75.2 & 0.27 & 2.5 & 7.1 & 193 & 1 & 1 & 1 \\
\hline 60.9 & 0.27 & 2.5 & 7.1 & 97 & -1 & -1 & -1 \\
\hline 59.6 & 0.15 & 3 & 7.1 & 120 & 1 & 1 & -1 \\
\hline 140.8 & 0.15 & 1.5 & 7.1 & 177 & 1 & 1 & 1 \\
\hline 140.8 & 0.15 & 1.5 & 7.1 & 199 & 1 & 1 & 1 \\
\hline 48.1 & 0.42 & 2.5 & 7.1 & 145 & -1 & -1 & -1 \\
\hline 69.8 & 0.25 & 3 & 7.1 & 162 & -1 & -1 & -1 \\
\hline 59.5 & 0.25 & 3 & 7.1 & 171 & -1 & -1 & -1 \\
\hline 110.9 & 0.5 & 4 & 6.9 & 174 & -1 & -1 & -1 \\
\hline 111 & 0.12 & 3 & 6.9 & 179 & 1 & 1 & 1 \\
\hline & & & & & & & \\
\hline
\end{tabular}

Table 4 Performance of testing dataset for both models using radial basis function

\begin{tabular}{|c|c|c|c|c|c|c|c|}
\hline \multirow[t]{2}{*}{$\sigma_{\mathrm{v}}^{\prime}$} & \multirow[t]{2}{*}{$\mathrm{a}_{\max }$} & \multirow{2}{*}{$\begin{array}{l}\text { Soil } \\
\text { type }\end{array}$} & \multirow[t]{2}{*}{$\mathrm{M}$} & \multirow[t]{2}{*}{$\mathrm{V}_{\mathrm{s}}$} & \multirow{2}{*}{$\begin{array}{c}\text { Actual } \\
\text { class }\end{array}$} & \multicolumn{2}{|c|}{ Predicted class } \\
\hline & & & & & & $\begin{array}{l}\text { Model } \\
\text { I }\end{array}$ & $\begin{array}{c}\text { Model } \\
\text { II }\end{array}$ \\
\hline 58.2 & 0.36 & 4 & 7.7 & 154 & -1 & -1 & -1 \\
\hline 140.8 & 0.32 & 1.5 & 7.7 & 199 & 1 & 1 & 1 \\
\hline 35.3 & 0.12 & 1 & 7.1 & 122 & -1 & -1 & -1 \\
\hline 53.9 & 0.13 & 1.5 & 6.5 & 127 & 1 & 1 & 1 \\
\hline 123.5 & 0.32 & 2.5 & 7.7 & 158 & -1 & -1 & -1 \\
\hline \multirow[t]{2}{*}{$\sigma_{\mathrm{V}}^{\prime}$} & \multirow[t]{2}{*}{$a_{\max }$} & \multirow{2}{*}{$\begin{array}{l}\text { Soil } \\
\text { type }\end{array}$} & \multirow[t]{2}{*}{$\mathrm{M}$} & \multirow[t]{2}{*}{$\mathrm{V}_{\mathrm{s}}$} & \multirow{2}{*}{$\begin{array}{c}\text { Actual } \\
\text { class }\end{array}$} & \multicolumn{2}{|c|}{ Predicted class } \\
\hline & & & & & & $\begin{array}{l}\text { Model } \\
\text { I }\end{array}$ & $\begin{array}{c}\text { Model } \\
\text { II }\end{array}$ \\
\hline 53.9 & 0.27 & 1.5 & 5.9 & 127 & -1 & -1 & -1 \\
\hline 57.8 & 0.36 & 1 & 5.9 & 105 & -1 & -1 & -1 \\
\hline 49.4 & 0.36 & 4 & 6.9 & 109 & -1 & -1 & -1 \\
\hline 38.3 & 0.36 & 4 & 6.9 & 122 & -1 & -1 & -1 \\
\hline 53.9 & 0.13 & 1.5 & 6.5 & 124 & 1 & 1 & 1 \\
\hline 35.4 & 0.22 & 1.5 & 6.6 & 133 & 1 & 1 & 1 \\
\hline 35.4 & 0.04 & 1.5 & 6.2 & 146 & 1 & 1 & 1 \\
\hline 35.4 & 0.18 & 1.5 & 6.2 & 127 & 1 & 1 & 1 \\
\hline 35.4 & 0.16 & 1.5 & 7.6 & 146 & 1 & 1 & 1 \\
\hline 53.9 & 0.12 & 1.5 & 5.9 & 124 & 1 & 1 & 1 \\
\hline 48 & 0.03 & 2 & 5.9 & 131 & 1 & 1 & 1 \\
\hline 57.8 & 0.2 & 1.5 & 6.5 & 115 & 1 & 1 & 1 \\
\hline 48 & 0.18 & 2 & 6.5 & 133 & 1 & 1 & 1 \\
\hline 60.9 & 0.14 & 2 & 7.1 & 131 & -1 & -1 & -1 \\
\hline 46.6 & 0.02 & 2.5 & 5.9 & 164 & 1 & 1 & 1 \\
\hline 40.5 & 0.36 & 4 & 6.9 & 94 & -1 & -1 & -1 \\
\hline 78.8 & 0.24 & 2.5 & 7.1 & 146 & -1 & -1 & -1 \\
\hline 81.7 & 0.24 & 3 & 7.1 & 176 & -1 & -1 & -1 \\
\hline
\end{tabular}




\begin{tabular}{|c|c|c|c|c|c|c|c|}
\hline 59.6 & 0.27 & 2.5 & 7.1 & 125 & -1 & -1 & -1 \\
\hline 62.1 & 0.19 & 4 & 7.1 & 136 & 1 & 1 & -1 \\
\hline 140.8 & 0.15 & 1.5 & 7.1 & 200 & 1 & 1 & 1 \\
\hline 120.2 & 0.06 & 2 & 6 & 195 & 1 & 1 & 1 \\
\hline 46.9 & 0.25 & 3 & 7.1 & 116 & -1 & -1 & -1 \\
\hline 35.4 & 0.04 & 1.5 & 6.2 & 130 & 1 & 1 & 1 \\
\hline 140.8 & 0.32 & 1.5 & 7.7 & 195 & 1 & 1 & 1 \\
\hline 90.1 & 0.12 & 1.5 & 7.1 & 147 & -1 & -1 & -1 \\
\hline 53.9 & 0.27 & 1.5 & 5.9 & 124 & -1 & -1 & -1 \\
\hline 46.3 & 0.36 & 4 & 6.9 & 134 & -1 & -1 & -1 \\
\hline 35.4 & 0.22 & 1.5 & 6.6 & 146 & 1 & 1 & 1 \\
\hline 35.4 & 0.18 & 1.5 & 6.2 & 146 & 1 & 1 & 1 \\
\hline 57.8 & 0.12 & 1.5 & 5.9 & 115 & 1 & 1 & 1 \\
\hline 57.8 & 0.21 & 1 & 6.5 & 105 & 1 & 1 & 1 \\
\hline 35.4 & 0.05 & 1.5 & 6.2 & 133 & 1 & 1 & 1 \\
\hline 86.2 & 0.24 & 3 & 7.1 & 142 & -1 & -1 & -1 \\
\hline 49.8 & 0.42 & 2 & 7.1 & 158 & 1 & 1 & -1 \\
\hline
\end{tabular}

\begin{tabular}{|c|c|c|c|c|c|c|c|}
\hline 58.2 & 0.19 & 4 & 7.1 & 154 & 1 & 1 & 1 \\
\hline 33.4 & 0.19 & 4 & 8.3 & 79 & -1 & -1 & -1 \\
\hline 97.7 & 0.16 & 3 & 7.5 & 163 & 1 & 1 & 1 \\
\hline 46.2 & 0.36 & 4 & 6.9 & 107 & -1 & -1 & -1 \\
\hline 84.7 & 0.16 & 1.5 & 7.1 & 135 & -1 & -1 & -1 \\
\hline 46.6 & 0.03 & 2.5 & 5.9 & 173 & 1 & 1 & 1 \\
\hline 44.5 & 0.16 & 3 & 7.5 & 118 & 1 & -1 & -1 \\
\hline 48 & 0.5 & 2 & 6.5 & 133 & -1 & -1 & -1 \\
\hline 82 & 0.16 & 2 & 7.1 & 148 & 1 & 1 & -1 \\
\hline 123.5 & 0.15 & 2.5 & 7.1 & 158 & 1 & 1 & -1 \\
\hline 69.2 & 0.14 & 2 & 7.1 & 136 & -1 & -1 & -1 \\
\hline 35.4 & 0.18 & 1.5 & 6.6 & 133 & 1 & 1 & 1 \\
\hline 54.4 & 0.15 & 3 & 7.1 & 153 & -1 & -1 & -1 \\
\hline 53.1 & 0.25 & 2.5 & 7.1 & 150 & -1 & -1 & -1 \\
\hline 46.6 & 0.5 & 2.5 & 6.5 & 173 & 1 & 1 & 1 \\
\hline 83.1 & 0.24 & 3 & 7.1 & 157 & -1 & -1 & -1 \\
\hline & & & & & & & \\
\hline
\end{tabular}

Table 5 Performance of Additional dataset* for both models using radial basis function.

\begin{tabular}{|c|c|c|c|c|c|c|c|c|}
\hline Site name & $\sigma^{\prime}{ }_{\mathrm{v}}$ & $\mathrm{a}_{\max }$ & $\begin{array}{c}\text { Soil } \\
\text { type }\end{array}$ & $\mathrm{M}$ & $\mathrm{V}_{\mathrm{s}}$ & \multirow{2}{*}{$\begin{array}{c}\text { Actual } \\
\text { class }\end{array}$} & & \multicolumn{2}{|c|}{ Predicted class } \\
\cline { 7 - 10 } & & & & & Model I & Model II \\
\hline Larter Ranche & 39 & 0.5 & 1.5 & 6.9 & 176 & -1 & -1 & -1 \\
\hline Larter Ranche & 38.4 & 0.5 & 1.5 & 6.9 & 153 & -1 & -1 & 1 \\
\hline Larter Ranche & 40.5 & 0.5 & 1.5 & 6.9 & 183 & -1 & -1 & -1 \\
\hline Whisky Springs & 38.2 & 0.5 & 1.5 & 6.9 & 181 & -1 & -1 & -1 \\
\hline Whisky Springs & 31.7 & 0.5 & 1.5 & 6.9 & 210 & -1 & 1 & -1 \\
\hline
\end{tabular}

*Ref: Andrus, R. D., and Stokoe, K. H. (1997).

\section{CONCLUSIONS}

The application of Support Vector Machine (SVM) model in liquefaction prediction is presented in this study. This paper has demonstrated the usefulness of the SVM to model the complex relationship between the seismic parameters and soil parameters. The performance of the SVM model is improved as more input variables are provided. Model I based on soil characteristics predicts the liquefaction potential very accurately with the available training and testing data. The effect of $\mathrm{C}$ on model accuracy and number of support vectors has been investigated and presented. The optimum values of $\mathrm{C}$ and the kernel are selected based on a parametric study. The model II ( based on shear wave velocity) presented clearly that only three parameters $\left\{\right.$ Vs, $a_{\max }$, and $\left.M\right\}$ are sufficient for predicting liquefaction potential of a site with depth. One major advantage of the SVM is its optimization algorithm, which provides global minima in comparison to the presence of local minima due to the use of a non-linear optimization problem with neural network approach. Other advantage with SVM is that it uses data points (called support vectors) closest to the hyperplane in classification process. The SVM models are simpler to apply than the conventional methods.

\section{ACKNOWLDGEMENTS}

This manuscript has been submitted for the possible publication in the journal of Computers and Geotechnics. 


\section{REFERENCES}

1. Marcuson WF. III Definition of terms related to Liquefaction, J. Geotech. Engrg. Div. ASCE 1978; 104(9):1197-1200.

2. Seed HB and Idriss IM (1967). Analysis of soil liquefaction: Niigata earthquake. J. Soil Mech. And Foun. Div ASCE 1967; 93(3):83-108.

3. Seed, H.B. and Idriss IM. simplified procedure for evaluating soil liquefaction potential. J. soil Mech and Found. Div. ASCE 1971, 97(9):1249-1273.

4. Seed HB, Idriss IM and Arango I. (1983). Evaluation of liquefaction potential using field performance data. J. Goetech. Engrg. Div ASCE 1983; 109(3):458-482.

5. Seed HB, Tokimatsu K, Harder LF, and Chung RM. Influence of SPT procedures in soil liquefaction resistance evaluation. Rep. No. UCB/EERC-84/15, Earthquake Engrg. Res. Ctr., Univ. of California, Berkeley, Calif 1984.

6. Robertson PK and Campanella RG. Liquefaction potential of sands using the cone penetration test. Journal of the Geotechnical Engineering Dividions ASCE 1985; 111(GT3):384-403.

7. Skempton AW. Standard penetration test procedures and the effects in sands of overburden pressure, relative density, particle size, aging and overconsolidation. Geotechnique 1986; $36(3): 425-447$.

8. Seed HB, and de Alba P. (1986). Use of SPT and CPT tests for evaluating the liquefaction resistance of sands. Use of in situ tests in geotechnical engineering, Geotech. Spec ASCE 1986;. 6.

9. Stark T D and Olson S M. Liquefaction resistance using CPT and field case histories. J. Geotech. Engrg. ASCE 1995; 121(12):856-869.

10. Olsen RS. Cyclic liquefaction based on the cone penetrometer test. Proc., NCEER Workshop on Evaluation of Liquefaction Resistance of Soils, Tech. Rep. NCEER-97-0022, T. L. Youd and I. M. Idriss,eds., National Center for Earthquake Engineering Research, Buffalo 1997, 225-276.

11. Robertson PK and Wride CE. Evaluating cyclic liquefaction potential using the cone penetration test.'Can. Geotech. J 1998; 35(3):442-459.

12. Dobry R, Stokoe KH, Ladd RS and Youd TL. Liquefaction susceptibility from S-wave velocity. Proc., ASCE Nat. Convention, In Situ Tests to Evaluate Liquefaction Susceptibility, ASCE, New York 1981.

13. Stokoe KH, II Nazarian S, Rix GJ, Sanchez-Salinero I, Sheu JC and Mok Y J. (1988a). 'In situ seismic testing of hard-to-sample soils by surface wave method." Earthquake engineering and soil dynamics II-Recent advances in ground-motion evaluation, Geotech. Spec. Publ., J. L. Von Thun, ed., ASCE, New York 1988a; 20:264-289.

14. Tokimatsu $\mathrm{K}$ and Uchida A. Correlation between liquefaction resistance and shear wave velocity. Soils and Found 1990; 30(2):33-42.

15. Andrus RD, Stokoe KH, and Chung RM.. Draft guidelines for evaluating liquefaction resistance using shear wave velocity measurements and simplified procedure. NISTIR 6277, National Institute of Standards and Technology, Gaithersburg, Md 1999.

16. Andrus RD and Stokoe KH. Liquefaction resistance of soils from shear wave velocity. J. Geotech. and Geoenvir. Engrg ASCE 2000; 126(11):1015-1025.

17. Juang $\mathrm{CH}$, Chen JC and Jiang T. probabilistic framework for liquefaction potential by shear wave velocity. J. Geotech. and Geoenvir. Engrg ASCE 2001; 127(8): 670-678.

18. Goh ATC. Probabilistic neural network for evaluating seismic liquefaction potential. Cnadian geotechnical journal 2002; 39:219-232.

19. Park D and Rilett L R. Forecasting freeway link ravel times with a multi-layer feed forward neural network. Computer Aided Civil And Znfa Structure Engineering 1999; 14:358 - 367.

20. Kecman V. Leaming And Soft Computing: Support Vector Machines, Neural Networks, And Fuzzy Logic Models, The MIT press, Cambridge, Massachusetts, London, England 2001. 
21. Vapnik, V. (1995). The nature of statistical learning theory, Springer, New York.

22. Andrus RD, and Stokoe KH. 'Liquefaction resistance based on shear wave velocity. Proc., NCEER Workshop on Evaluation of Liquefaction Resistance of Soils, Tech. Rep. NCEER-970022, T. L. Youd and I. M. Idriss, eds., Nat. Ctr. for Earthquake Engrg. Res., State University of New York at Buffalo, Buffalo 1997; 89-128.

23. Whitman RV. Resistance of soil to liquefaction and settlement. Soil and Foundations 1971; 11(4):59-68.

24. Boser BE, Guyon IM, and Vapnik VN. A training algorithm for optimal margin classifiers. In D. Haussler, editor, 5th Annual ACM Workshop on COLT, pages 144-152, Pittsburgh, PA, ACM Press 1992.

25. Cortes C, Vapnik VN. Support vector networks. Machine Learning 1995; 20:273-297.

26. Gualtieri, J.A, Chettri,S.R., Cromp, R.F., and Johnson,L.F. Support vector machine classifiers as applied to AVIRIS data. In the Summaries of the Eighth JPL Airbrone Earth Science Workshop 1999.

27. Vapnik VN. Statistical learning theory, New York: Wiley 1998.

28. Fletcher R . Practical methods of optimization(2nd ed.). Chichester; Newyork:Wiley 1987.

29. Cristianini N and Shawe-Taylor J. an introduction to Support vector machine. London, Cambridge University press 2000.

30. Watanachaturaporn P, Varshney PK and Arora MK. Evaluation of factors affecting support vector machines for hyperspectral Classification. The American Society for Photogrammetry \& Remote Sensing 2004.

31. Sincero AP. Predicting Mixing Power Using Artificial Neural Network. EWRI World Water and Environmental 2003.

32. Shahin, M.A., Jaksa, M.B. \& Maier, H.R. Predicting the settlement of shallow foundations on cohesion less soils using back-propagation neural networks. Dept. of Civil and Envi. Eng., University of Adelaide, Australia, 2000; R167.

33. MathWork Inc. Matlab user's manual, Version 5.3. Natick, MA: The MathWorks, Inc 1999. 